\title{
BMJ Open Patients' perceived value of pharmacy quality measures: a mixed-methods study
}

\author{
Olayinka O Shiyanbola, ${ }^{1}$ Jane R Mort ${ }^{2}$
}

To cite: Shiyanbola 00, Mort JR. Patients' perceived value of pharmacy quality measures: a mixed-methods study. BMJ Open 2015;5: e006086. doi:10.1136/ bmjopen-2014-006086

- Prepublication history and additional material is available. To view please visit the journal (http://dx.doi.org/ 10.1136/bmjopen-2014006086).

Received 9 July 2014

Revised 9 December 2014 Accepted 17 December 2014

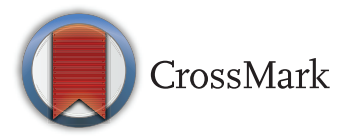

${ }^{1}$ Division of Social and Administrative Sciences, School of Pharmacy, University of WisconsinMadison, Madison, Wisconsin, USA ${ }^{2}$ Department of Pharmacy Practice, College of Pharmacy, South Dakota State University, Brookings, South Dakota, USA

\section{Correspondence to} Dr Olayinka 0 Shiyanbola; oshiyanbola@pharmacy.wisc. edu

\section{ABSTRACT}

Objective: To describe patients' perceived value and use of quality measures in evaluating and choosing community pharmacies.

Design: Focus group methodology was combined with a survey tool. During the focus groups, participants assessed the value of the Pharmacy Quality Alliance's quality measures in evaluating and choosing a pharmacy. Also, participants completed questionnaires rating their perceived value of quality measures in evaluating a pharmacy (1 being low value and 5 being high) or choosing a pharmacy (yes/no). Thematic analysis and descriptive statistics were used to analyse the focus groups and surveys, respectively. Setting: Semistructured focus groups were conducted in a private meeting space of an urban and a rural area of a Mid-western State in the USA.

Participants: Thirty-four adults who filled prescription medications in community pharmacies for a chronic illness were recruited in community pharmacies, senior centres and public libraries.

Results: While comments indicated that all measures were important, medication safety measures (eg, drugdrug interactions) were valued more highly than others. Rating of quality measure utility in evaluating a pharmacy ranged from a mean of 4.88 ('drug-drug interactions') to a mean of 4.0 ('absence of controller therapy for patients with asthma'). Patients were hesitant to use quality information in choosing a pharmacy (depending on the participant's location) but might consider if moving to a new area or having had a negative pharmacy experience. Use of select quality measures to choose a pharmacy ranged from $97.1 \%$ of participants using 'drug-drug interactions' (medication safety measure) to $55.9 \%$ using 'absence of controller therapy for patients with asthma'.

Conclusions: The study participants valued quality measures in evaluating and selecting a community pharmacy, with medication safety measures valued highest. The participants reported that the quality measures would not typically cause a switch in pharmacy but might influence their selection in certain situations.

\section{BACKGROUND}

It has been proposed that the public reporting of provider quality of care can increase

\section{Strengths and limitations of this study}

- This is the first study to consider patient perceptions of the value of pharmacy quality measures. This is an important first step for pharmacy performance measures to be utilised by patients.

- This is the only study to examine whether patients perceive pharmacy quality measures that may be seen in public reports as valuable or useful in their health provider selection.

- Researchers have not examined variations of importance among pharmacy quality measures. This study is significant in improving the quality of healthcare provided by providers as the pharmacy profession moves towards developing publicly available reports intended to enhance the quality of care received by patients.

- Small sample size.

- Limited geographical area.

- Predominantly Caucasian sample population which limits the ability to generalise the study findings to other racial/ethnic groups.

the quality of healthcare including the accountability and transparency of care delivered to patients. ${ }^{1}{ }^{2}$ While research on the influence of quality-of-care information on patients' healthcare provider choice has yielded mixed results, ${ }^{3}$ it is clear that patients want quality-of-care information and are concerned about choosing a high-quality provider. $^{4-10}$

For some time, patients have been using quality measures to examine healthcare in a variety of settings. ${ }^{11} 12$ The possibility of publicly reported pharmacy quality information emerged with the development of measures by a USA consensus-based non-profit organisation called the Pharmacy Quality Alliance (PQA) ${ }^{13}$ The mission of PQA is to improve healthcare quality and patient safety through a process of measuring pharmacy and pharmacist performance and reporting this information in a meaningful way to patients, pharmacists, employers, health insurance plans and other healthcare decision-makers. The intent is for them to use this information 
to make informed choices and improve outcomes. ${ }^{13} 14$ PQA developed medication use quality performance measures in areas including adherence, medication safety and appropriateness. The specific measures included adherence measures: proportion of days covered; medication safety measures: diabetes medication dosing, use of high-risk medications in the elderly and drug-drug interactions; and appropriateness measures: suboptimal treatment of hypertension in patients with diabetes and medication therapy for persons with asthma. ${ }^{13}$ However, certain issues such as patient perceptions of the value of quality measures need to be considered if pharmacy performance measures are to be utilised successfully by patients.

Testing patients' perception of the importance and usefulness of public reports has been found to be essential in assuring a responsive and accountable system of care. ${ }^{4}$ However, a major area of research not currently investigated is whether patients perceive pharmacy quality measures that may be seen in public reports as valuable or useful. It is important to understand patients' views on publicly reported quality measures in selecting health providers, especially if the intent of the measures is to encourage selection of high-quality providers.

Hibbard et $a l^{15}$ proposed a theoretical consumer choice model that represents the process involved in the utilisation of comparative quality information to select health providers. According to this model, patients must trust the quality information and view it as useful to them before it can be used in their decision-making. ${ }^{15}$ In addition, using quality information to choose providers has been noted to increase if the patient is not satisfied with their current provider or if the patient is forced to change their present provider due to a new insurance policy or new disease condition. ${ }^{16-18}$ In a Taiwan study, a majority of survey respondents would change their physician if they performed badly in a quality report. ${ }^{8}$ Also, restricted health provider access is identified as a factor that might influence the use and perceived value of quality information. ${ }^{3}$ While tremendous work has been carried out to identity patients' possible use of quality information in physician and health plan decision-making, no one has considered the usefulness of quality measures to choose or switch pharmacies. Therefore, it is important to investigate whether pharmacy-based quality measures are useful to patients when choosing a community pharmacy.

Hibbard and Jewett, ${ }^{19}$ showed that there are variations in the importance of different quality indicators. For example, patient ratings of providers and quality measures examining preventive care have been shown to be useful to patients in their selection of providers compared with measures of adverse event occurrence. ${ }^{5}$ No one has considered if there are similar variations in importance among pharmacy-based quality measures. This is significant as the pharmacy profession moves towards developing publicly available reports intended to enhance the quality of care received by patients.
This study examined the usefulness of pharmacy quality measures in a patient's evaluation of a community pharmacy. Pilot study results suggest the personal relevance of a quality measure influences perceived utility. ${ }^{20}$ In the present study, we further examine the potential utilisation of quality measures in evaluating, choosing and switching a community pharmacy. We assess the potential use of pharmacy report cards by patients with self-reported chronic illnesses and describe whether patients who have a high probability of using pharmacies might utilise quality measures when deciding which pharmacy to use. It was hypothesised that each specific quality measure would be valued differently and certain pharmacy quality measures would influence the community pharmacy choice of individuals with chronic illnesses.

The objectives of the study were to:

1. Describe patients' use of pharmacy quality measures in evaluating, choosing and switching a community pharmacy.

2. Examine patients' perceived value of specific pharmacy quality measures.

\section{METHODS}

\section{Design and sample}

Semistructured focus groups were conducted among adult men and women who could speak and understand English, self-reported a chronic illness diagnosed by their health provider, used a community pharmacy to fill their prescriptions and currently took a prescription medication. A questionnaire was also administered during the focus group. Sampling was by convenience and participants were recruited from a rural and an urban area in a Mid-western State. Recruitment was carried out in community pharmacies, a senior centre, and a public library using newsletters, flyers, radio announcements and word of mouth. The Institutional Review Board of the investigator's university approved the study.

\section{Data collection}

Focus groups lasting 60-90 min were used to examine participants' perceived value of the PQA quality measures. Participants discussed their perceptions of the importance of each pharmacy quality measure and all quality measures together. Also, participants described their possible use of the quality measures to choose and switch their pharmacies. The focus group questions were open-ended, worded neutrally and developed by the research team with revisions and feedback from a PQA collaborator. The script used in this study was previously utilised in our pilot study but was modified to meet this study's objectives ${ }^{20}$ (see online supplementary appendices 1 and 2).

Patient-friendly phrasings and definitions of the PQA pharmacy quality measures were presented to the study participants and used in the discussion. These included: Adherence measures 
1. Helping patients get needed medications (The pharmacy ensured that patients received the medicines for their chronic conditions and continued to receive them on a regular basis)

Medication safety measures

2. Diabetes medication dosing (The pharmacy ensured that patients were not dispensed a dose higher than the recommended dose for diabetes medications)

3. Use of high-risk medications in the elderly (The pharmacy ensured that the elderly did not receive a medication that could put them at high risk for developing a severe health problem)

4. Drug-drug interactions (The pharmacy ensured that there were no patients who were dispensed two medications that could cause harm when taken together)

\section{Appropriateness measures}

5. Suboptimal treatment of hypertension in patients with diabetes (In a pharmacy, people who have diabetes and high blood pressure were not getting the best medications to treat blood pressure in people with diabetes)

6. Absence of controller therapy for patients with asthma (In a pharmacy, patients with asthma were using many 'rescue' inhalers to treat their asthma attacks when they occurred but were not getting medications to prevent asthma attacks)

Audio recordings of the focus groups were carried out digitally and the investigator or research assistant moderated the sessions. Two focus groups were conducted in the rural area of a Mid-western State (rural town of about 3000 people) and four focus groups were conducted in an urban area of the state (a population of about 150000 people).

During the focus groups, participants were given questionnaires to complete. Using rankings, the questionnaire assessed participants' perceived value of each PQA quality measure in the evaluation of their community pharmacy, the possible use of each quality measure in choosing/switching their pharmacy and overall perceptions of the quality measures. Specifically, participants rated on a scale of 1-5 ( 1 being low and 5 being high) how much they valued each specific quality measure in evaluating a pharmacy. Also, using yes and no responses, participants indicated if they would use quality measures (including each specific quality measure) to choose a pharmacy; if they would switch to a higher quality pharmacy based on a lower quality rating in their current pharmacy; and if they would switch pharmacies based on lower ratings on specific quality measures in their current pharmacy. Participants' responses were collected anonymously and each participant received a $\$ 20$ gift card as compensation for participating in the study.

\section{Data analysis}

All focus group discussions were transcribed verbatim by a certified transcriber. Thematic analysis was used to examine whether quality measures would influence participants' choice of pharmacy and their perceived value of pharmacy quality measures. Emergent themes related to the variance of the quality measures among pharmacies before switching pharmacies were described. Using the transcribed notes and abstracted units of statements and sentences, themes and subthemes were elicited. Transcripts were coded separately by the investigators and two research assistants and potential themes were collated based on the focus group questions. Other emergent themes from the focus groups were examined. Themes from each coder were compared to examine consistency of themes. Descriptive statistics examined the survey questions on value and use of quality measures. All survey questions were statistically analysed using SPSS V.21.0.

\section{RESULTS}

Overall, there were 34 participants in this study (12 in the rural area and 22 in the urban area). Participants had a mean age of 62.85 years $(\mathrm{SD}=16.05)$. Most participants were female $(n=26,76.5 \%)$, Caucasian $(n=31$, $91.2 \%)$, had a college degree $(\mathrm{n}=12,35.3 \%)$ and reported fair health $(\mathrm{n}=12,35.3 \%)$. The mean number of medications used daily was $4.18 \pm 3.53$ and the mean

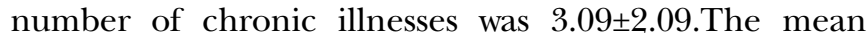
number of pharmacies used to fill prescriptions was 1.44 \pm 0.71 and most participants used a chain pharmacy $(n=19,55.9 \%$; full results can be seen in reference 21$){ }^{21}$ On the basis of the study aims, three major themes were identified from the focus groups.

First, patients are hesitant to use quality information to choose/switch their pharmacies, but would consider the use of provider quality information if they were new to an area, had a previous negative pharmacy experience, and were aware of such performance information. Second, patients' perception on the use of quality information to switch pharmacies differed by the participants' place of residence (urban vs rural). Third, patients thought all the pharmacy quality measures were important in the evaluation of pharmacies but seemed to value certain measures more than others depending on whether they had the chronic condition identified in the quality measure. Additional themes were also described.

Our overall findings are grouped based on the objectives of the study. In objective 2, we examine the patients' perceived value of each specific quality measure and we specifically discuss the findings based on their medication use category.

\section{Objective 1}

The objective was to describe patients' use of pharmacy quality measures in evaluating, choosing and switching a community pharmacy.

Although patients were likely to consider using quality measures, there was still some hesitation regarding how to utilise the information because of insufficient knowledge.

I don't know if I would use it or not. I've never had to use anything like that before. 
Major theme 1: Patients thought they would use quality measures in evaluating and choosing a pharmacy in certain situations. For example, if they had a negative experience with their current pharmacy which might have validated the data; if they were aware of the available pharmacy quality information; or if they were moving to a new area (table 1).

Verbatim statements included:

Well, if it was real disastrous, I probably would switch... If they are giving the wrong prescriptions, I don't want to take that chance with me

I'd have to have some really negative information before I'd switch

The only reason I'd change is if they do something to me personally or someone I know. I can validate that error, then I would change

Well, if I was moving to a new area, I probably would use the information. You want the best available

Other minor themes were identified:

Patients thought some measures might be more helpful than others in deciding whether to switch pharmacies.

If it's something kind of serious like they've been dispensing the wrong drugs or something, then I definitely would go to a different one.

Yeah, I would switch.- they don't have my health in mind...especially the drug-to-drug interactions. They're dispensing something that they know would react to something else, and they're not doing anything about it, I'd be gone in a heartbeat.

Some individuals were hesitant to change their pharmacies based on quality measures. They noted that they would stay with their pharmacies as long as they still had a personal positive experience and ask the pharmacist about a poor score they might have seen in a public report.

I'd probably consider it. I don't know if it'd be yes or no for sure. But I would consider it. If I had a good experience at my pharmacy, I would keep using it. However, if it had a bad score, I would inquire. I would ask them why they were getting these bad scores because my personal experience has been good.

Major theme 2: Patients perceptions on whether they would switch their pharmacy based on quality information also seemed to differ by their place of residence. In the urban setting, most participants agreed that they would consider using pharmacy quality measures to switch their community pharmacies (table 1 ).

I'd switch in a heartbeat. I would. See, it would be for anything. You know, people with diabetes should have the same quality of care coming out of their pharmacy, and I would look at that. If they're rated low, what else are they rated low at? Maybe down the road, I could develop it, and then I would have to change pharmacies because their rating was low, and I wouldn't trust them to monitor my medication. I mean, if they can't watch the elderly, and the elderly you know, have times where they don't always remember, and they need that pharmacy to help them keep on track of what they're taking and what they're not. It's all important to me

Yeah, no matter how well I like it there or like who is there, my health is way more important than any of them! It takes one time and you're dead!

In the rural area, patients were hesitant/not sure of whether they would use quality information in their pharmacy decision-making/pharmacy switch because of the good credibility of available pharmacies, limited pharmacy choices in the area, and personal relationships with the owners of the pharmacies they used (table 1). Verbatim statements included:

Oh, where I'm living right now to switch to a different pharmacy-no, I don't think so. I can see that making a difference more like in a bigger town. (Urban Town name) versus in (Small town name)...because in (Small town name), it's a smaller community, and you know the people in the pharmacy better. You know the pharmacy better

In a (Urban town name) pharmacy, there's more people going into the pharmacy every day. And the people in the pharmacy are seeing more people. To me, you know more about what's going on in a pharmacy in a small town than what you would in (Urban town name)

Other minor themes identified included:

\section{Number of pharmacies available may influence use of quality information}

To me, the most use I would ever get out of the data wassay I'm retired and move into a new place where I have no idea what any of the pharmacies are. I would definitely use the data. Here it's not such a big deal 'cause there's only two options really unless you're going mail-order...

There's not much choice here. Also... We have two wonderful pharmacies and have no problem with any of them. We have nothing to complain about

I can see where... You have six different pharmacies, and you want to know if (pharmacy name) is better at doing well than what (Pharmacy name) or (Pharmacy name) does

\section{Credibility of pharmacies influence the probability of switching}

It's hard to say here (whether I would switch or not) when we do have two good pharmacies. I think they are pretty even 


\section{Objectives and themes \\ Describe patients' use of pharmacy quality} measures in evaluating, choosing and switching a pharmacy

Theme 1: Patients are hesitant to use quality information to choose their pharmacy but may consider its use in certain situations

Theme 2: Patients' perception of the use of quality information to switch pharmacies differs by geographical location

Examine patients' perceived value of pharmacy quality measures

Theme 3: Patients with chronic illnesses think pharmacy quality measures are important in the evaluation of a pharmacy

Theme 4: Patients' perceived value of pharmacy quality measures differ for each measure

Other themes

Source and credibility of the quality ratings Differential in quality measures before pharmacy switch

\section{Perceptions}

Use of pharmacy quality measures in decision-making

Perceived value of quality measures
Patients living in an urban location are likely to consider using quality measures to switch pharmacies

Patients living in a rural area are unsure of using quality information to switch pharmacies because of the limited number of pharmacies available, established personal relationships with pharmacy owners and the calibre of pharmacies in the small town

Patients think all PQA-approved pharmacy quality measures are important. However, some participants seem to value certain measures more highly tha others Patients' value of pharmacy quality measures is personal to each individ
certain individuals seem to value specific measures depending on their preferences and whether they had the chronic condition associated with the measure

rating system if they we to use the information in their pharmacy selection

Patients want to see a big difference in the pharmacy ratings being compared before they make a switch

Some patients stated that the difference depended on the specific measure

they were using to evaluate the pharmacy

\section{Sample quotations}

"I don't know if I would use it or not. I've never had to use anything like that before"

"I can see where people would use something like this if all of a sudden they (the pharmacy) had mistakes": "So, if you got disgusted or you have an allergic (he phan that they didn't catch, if you knew this was avail you have an allergic reaction tick on and see how people have reviewed this one you' re going to you'd go on and see, for example, you have diabetes. There have been you'd go on and see, for example, you have diabetes. There have been mistakes. What is the quality? You're going to go use this kind of inform "Would possibly use it...If you knew it (quality information) was out there and "Would possibly use it...If you knew it (qualt

your pharmacy was actually being rated"
"I suppose if I had never been to a pharmacy before, you know. ..., let's say I II suppose if I had never been to a pharmacy before, you know. ..., let's say I anybody there, then how am I going to know what pharmacy's good"

'If it's something kind of serious like they've been dispensing the wrong drugs or something, then I definitely would go to a different one"

"If they are giving the wrong prescriptions, I don't want to take that chance with me"

oft of where you get it (prescriptions) from is probably based on some kind of personal relationship here in town because you know everyone. The people that get their stuff down there are friends with the owner or know them from church or something like that'

"To be a good pharmacy, I think all (the quality measures) should be up there. If they're lacking in something, well then do you really wanna go, "How important is it to me?" You know, "Is there a chance I could develop it?" "important is it to me?" You know, "Is there a chance I could develop it?" "To me, everything on here is important. They shouldn't drop anything because
they deal with so many types of patients, and they should be well-versed in diabetes and asthma and making sure there's not drugs being given to people that would interact with the drugs they're taking"

See, any of these (quality measures) is important. I mean, if they can't watch the elderly, and the elderly have times where they don't always remember, and they need that pharmacy to help them keep on track of what they're taking and what they're not. It's all important to me

"But a lot of people are more concerned about the condition they have, and they'll go to the pharmacy that they think is handling that condition the best" "I don't have diabetes, and l'm not asthmatic, so I don't see why that would pertain to me"

"Well, I hate to be biased, but with my conditions, I would rate this stuff that pertained to me higher...just because it pertains more to me, so I guess I'm biased"

"If it was...that-...they gave the wrong medication, I would not find that acceptable at all. It would give me pause for thought. Would I change pharmacy? l'd have to think about it. But it would certainly give me pause for thought. If they didn't follow-up and call a patient that it was time for their medication, that wouldn't make any difference to me"

"I don't know if I would (use quality information in pharmacy selection). I don't always trust the rating and who is rating it-and how much I know about the board that happens to be rating and how they're rating it... How they're saying "Well, this is a good pharmacy, and this is a little lower on the totem pole," and that. I guess I would rather go to them and find out myself"

"'d like to see a big difference before I would consider (switching pharmacies)" 'Well, on certain ones, I would imagine like even just a one or a two percent just because it's such an important one" 
Personal relationships influence pharmacy choice and may hinder the possibility of switching pharmacies

I feel like my answers for whether I would change pharmacies would be different if I lived in (Urban town name) than if I lived in (Small town name). I feel like your selection of pharmacy here (Small town) is based almost solely around personal relationship

\section{Survey results - use of quality measures to choose/switch pharmacy}

Using the questionnaires, most participants $(\mathrm{n}=32,94.1 \%)$ agreed that they would use quality measures information to choose their pharmacies. When asked if they would use each specific measure to choose their pharmacy, most patients agreed that they would use each measure. Absence of controller therapy for patients with asthma and suboptimal treatment of hypertension in patients with diabetes had the lowest number of participants who would use the measures to choose a pharmacy $(n=19,55.9 \%)$ and $(\mathrm{n}=22,64.7 \%)$, respectively (table 2 ).

Survey results showed that most patients would switch their pharmacies based on quality scores $(n=28,84.8 \%)$. All participants agreed that they would use drug-drug interactions as a measure in evaluating whether to switch their pharmacy but fewer participants would use suboptimal treatment of hypertension in patients with diabetes $(n=19,55.9 \%)$ and absence of controller therapy for patients with asthma $(n=21,61.8 \%$; table 3$)$.

\section{Objective 2}

The objective was to examine patients' perceived value of pharmacy quality measures (including its specific measures).

On the basis of the focus groups, patients thought all the PQA-approved quality measures were important in evaluating a pharmacy.

You don't know when you're going to get the condition or when it might change. So, I would think all the measures would be important all the time.

Table 2 Survey results showing the participants who would use quality measures (and specific pharmacy quality measures) to choose pharmacies $(n=34)^{\star}$

\begin{tabular}{ll}
\hline Quality measure & $\begin{array}{l}\text { Number } \\
(\%)\end{array}$ \\
\hline Drug-drug interactions & $33(97.1)$ \\
Helping patients get needed medications & $32(94.1)$ \\
Use of high-risk medications in the elderly & $27(79.4)$ \\
Diabetes medication dosing & $25(73.5)$ \\
$\begin{array}{l}\text { Suboptimal treatment of hypertension in } \\
\text { patients with diabetes }\end{array}$ & $22(64.7)$ \\
$\begin{array}{l}\text { Absence of controller therapy for persons } \\
\text { with asthma }\end{array}$ & $19(55.9)$ \\
All quality measures & $32(94.1)$ \\
\hline *Survey results were collected during the focus group discussions.
\end{tabular}

Major theme 3: Some participants valued certain measures in evaluating a pharmacy more highly than others did (table 4). The PQA quality measures medication use category is used in grouping these findings. These medication use areas include adherence, medication safety and appropriateness. For example, the adherence measure, helping patients get needed medication; and medication safety measures, drug-drug interactions, and use of high-risk medication in the elderly, were highly valued.

\section{Adherence measure \\ Helping patients get needed medication}

Well, I think it's pretty important because I have a friend who has the start of Alzheimer's. When she saw on her prescription bottle that no refills, she thought that meant that she wasn't supposed to take it. If she didn't get it refilled and the pharmacy followed up on it, when she hadn't had it refilled-that would be pretty important because it's critical medicine

Patients were concerned that the pharmacist would have time to ensure they were getting their needed medications if time was taken to perform these activities (table 4).

There was some uncertainty as to the role of the pharmacist in ensuring adherence to medicines and there were mixed feelings about receiving pharmacy calls concerning prescription refills.

How are pharmacies are going to ensure that patients received their medications. The pharmacies are not responsible for calling up the patients. I don't think it's their responsibility...

Some patients also questioned using medication adherence measures to evaluate a pharmacy.

If they didn't follow-up and call a patient that it was time for their medication, that wouldn't make any difference to me.

Table 3 Survey results showing the participants who would use quality measures (and specific pharmacy quality measures) to switch pharmacies $(n=34)^{\star}$

\begin{tabular}{ll}
\hline Quality measure & $\begin{array}{l}\text { Number } \\
\text { (\%) }\end{array}$ \\
\hline Drug-drug interactions & $34(100)$ \\
Helping patients get needed medications & $30(90.9)$ \\
Diabetes medication dosing & $25(73.5)$ \\
Use of high-risk medications in the elderly & $24(70.6)$ \\
$\begin{array}{l}\text { Absence of controller therapy for persons } \\
\text { with asthma }\end{array}$ & $21(61.8)$ \\
$\begin{array}{l}\text { Suboptimal treatment of hypertension in } \\
\text { patients with diabetes }\end{array}$ & $19(55.9)$ \\
All quality measures & $28(84.8)$ \\
\hline *Survey results were collected during the focus group discussions.
\end{tabular}


Table 4 Patient perceptions of the value of specific pharmacy quality measures in evaluating a pharmacy (focus groups)

\begin{tabular}{lll}
\hline Objective & Quality measure & Perceptions \\
\hline $\begin{array}{l}\text { Examine patients' } \\
\text { perceived value of }\end{array}$ & $\begin{array}{l}\text { Helping patients get } \\
\text { needed medication }\end{array}$ & $\begin{array}{l}\text { Patients thought this measure was important in } \\
\text { evaluating a pharmacy } \\
\text { measures }\end{array}$ \\
$\begin{array}{l}\text { Patients were concerned that the pharmacist } \\
\text { would have time to ensure they were getting th } \\
\text { needed medications and refills if time was take } \\
\text { to perform these activities }\end{array}$ \\
$\begin{array}{l}\text { There was some uncertainty in the role of the } \\
\text { pharmacist to ensure adherence to medicines } \\
\text { and mixed feelings on being called by the } \\
\text { pharmacy about prescription refills }\end{array}$
\end{tabular}

Drug-drug interactions

Diabetes medication dosing

Use of high-risk medication in the elderly

Suboptimal treatment of hypertension in patients with diabetes

Absence of controller therapy for patients with asthma
Patients noted that they relied on their pharmacists to ensure their medicines were not harming them

Sample quotations

"I sometimes don't watch how low I get on my medication. And then all of a sudden, I'm like, "Whoa." And I do need it. I have to call, and it needs to be faxed. It would be nice for a little reminder-"

"Yes, I think that (ensuring patients got their needed medication) would be good because I think people sometimes have a lapse in their medications, and it hurts them a lot like for depression or something like that"

"How could they call everybody? It's not possible, I wouldn't think. They'd have to have a large staff" "I can see the need for it, but then I can also see that-hopefully, it's not going to be harassing either, you know. ...Sometimes I don't get my medicines all the time. A lot of times I can't afford to get it refilled right away. So, I might go a week without my medicine. But I don't want the pharmacy to be harassing me because I am between my pay period"

"I think it could be valuable if the pharmacist called up to remind the patient that they were due to have their prescription filled or that it was overdue. But I don't think to ensure"

"Pharmacists see interactions with drugs and everything else. That's part of their responsibility.

...I have a friend whose doctor prescribed her something that she was actually allergic to. The pharmacist knew all her drugs and drug interactions and actually caught it. I think that's one of the purposes of being a pharmacist like a second check with the doctor. That's very important. She could have died!"

"Yeah, I would switch-they don't have my health in mind. Especially the drug-to-drug interactions. They're dispensing something that they know would react to something else, and they're not doing anything about it, l'd be gone in a heartbeat!' "But why should that be left up to the pharmacist? The doctor should have prescribed it correctly" "I put medium for it (diabetes medication dosing). I'm not saying it's not important. It's just not personal. If two years down the road, I develop diabetes, then that would change"

Patients thought the measure was not as important since they did not have diabetes but noted that their perception of the measure could change if they developed the illness later Patients thought this measure was very important to consider when evaluating pharmacies

This quality measure was not highly valued and patients were not sure of the pharmacists' role related to the measure

Patients who had the particular chronic condition (asthma) seemed to value the measure highly
"It's (high risk medication in the elderly) extremely important because they (the elderly) don't understand. A lot of times they're lost. My mother-in-law wasn't getting medication she was supposed to be getting. She was getting stuff that was making her worse. They had not caught that. That's very important. Basically she had some serious memory problems and living in the past" "It's extremely important, but it's not nearly as important as doses (accurate diabetes medication dosing) and everything. The doctor should be catching your blood pressure. With diabetes, it will kill you a whole lot faster if you're not getting the right dose"

"See, the asthma does pertain to me, because I have two rescue inhalers that I can use up to every two hours. I also am on two other inhalers, a nasal spray, and a pill for my COPD... You know, if it takes a pharmacist to remind a doctor to say, 'Hey, this patent is utilizing an awful lot of rescue inhalers, you know, you may want to readdress her condition or something"' 


\section{Medication safety measures}

\section{Drug-drug interactions}

Drug-drug interactions was considered by patients as one of the most important quality measures to use in evaluating pharmacies (table 4).

I count on my pharmacy to make sure that neither one are prescribing something-that is higher or is going to react with something because I went through reactions already. It put me in the hospital for over a week. That's not going to happen! I really count on my pharmacy to make sure.

\section{Use of high-risk medication in the elderly}

Patients thought this quality measure was also important in evaluating a pharmacy (table 4).

\section{Diabetes medication dosing}

Diabetes medication dosing seemed to be of medium value. In some instances, patients noted that the value of the diabetes-related measure might change if they developed the chronic condition later (table 4)

I would hope that they give me accurate medications; not too much or not enough... Theoretically they have to be accurate. If they're not, then they better not be in pharmacy

\section{Appropriateness measures}

\section{Suboptimal treatment of hypertension in patients with} diabetes

This quality measure seemed to be of medium value. Patients were not sure if it was the role of the pharmacist to ensure that patients with diabetes were receiving an antihypertensive or the role of the physician.

So why is this (suboptimal treatment of hypertension in patients with diabetes) the pharmacist responsibility instead of the doctor's responsibility? That's what their doctor should know to start with...

\section{Absence of controller therapy for patients with asthma}

Patients who had the chronic condition (asthma) seemed to value the quality measure.

I'm on asthma medication-you know. I would like my pharmacy to say, "You're getting your rescue inhalers filled this many times, and I think you need to talk to your doctor about-"or him give the doctor a call! And he could say, "This patient of yours has filled their medication or inhalers this many times this month." So, we need to do something to prevent that. Yeah, we need to do something to prevent it instead of waiting 'til they've already got a full-blown asthma attack going on

Patients' perceived value for specific measures varied. Their decision to use quality information in pharmacy selection was based on the specific measure, individual preference, and if they had the chronic condition associated with the measure. Verbatim statements included:
What would make me switch? Well, it depends on what put them at 80 . You know, which one of these measures

I don't know that one would be more important than the other. They all seem important, depending on the person's needs

These measures are personal. Some of these measures depends on whether you have this (the condition) I suppose to a degree on whether you care so much. I have asthma, so I do care about asthma. I feel like you would probably only use (specific measures) to evaluate a pharmacy if those apply to you.

I don't have diabetes but I said yes (it is important) because my girlfriend is diabetic

Additional themes (table 1): Patients were concerned about the credibility of rating systems and wanted to be sure of the source of the ratings before using the information to make a decision.

\section{Source of the rating}

It all goes back to who is rating them and where the information is coming from.

\section{Differential in quality measures before making a switch in pharmacies}

Patients described how they wanted to see a big difference before they made a switch in their pharmacy depending on the rating system.

It would have to be a huge difference before I would switch.

I suppose if it was 30 and 90 I would switch, but 70 and 80 - I don't know. That's too close

It would have to be at ten percent or twenty percent for me to switch

Well, if there was a four star limit, and they only had one, I'd want to change. If they had three out of the four, I'm not so sure I would change

Other participants stated that the difference they would see before they made a switch depended on the specific measure they were using to evaluate the pharmacy, and the consideration of other convenience and cost factors. Verbatim statements included:

It all depends on which one of these categories! If it is overall categories, 20 percent (difference in pharmacy quality ratings) is huge on overall! If I don't have diabetes, and they're getting nicked on diabetes stuff, then I probably don't care so much. If it is drug-to-drug interaction, the gap is probably narrower. It's probably more like ten percent. So, it would depend on the measure

It probably wouldn't make that much difference (for me to switch) assuming a couple of things. It's not much less 
inconvenient to go there. It's not much more expensive or some of those types of things. There's other factors that are gonna factor in when you're picking a pharmacy other than how good they are. These (quality measures) are super helpful if I have (Pharmacy name) on one corner and (Pharmacy name) across the street and I live a mile away and I can drive and it's the same drive. If they're comparable or marginally worse, let's say, on healthcare ratings or their report card, I could probably live with that because it's more convenient

On the basis of the questionnaires, when participants were asked to rank the value of the measures in evaluating a pharmacy, a majority ranked each measure a value of 5 with the highest mean for medication safety measure, drugdrug interactions $($ mean $=4.88 \quad(\mathrm{SD}=0.33))$. The lowest means were reported for appropriateness measures, suboptimal treatment of hypertension in patients with diabetes (4.00 $(\mathrm{SD}=1.23))$, and absence of controller therapy for persons with asthma (mean=4.03 $(\mathrm{SD}=1.26)$; figure 1$)$.

\section{DISCUSSION}

In this study, individuals with chronic illnesses reported that they value quality measures in evaluating a community pharmacy with medication safety measures valued highest and more likely to be used to select pharmacies. Among the study participants, quality measures would not typically cause a switch in pharmacy but may influence selection in certain situations. The themes in this study that support these conclusions follow similar constructs found in two domains in the proposed consumer choice model. ${ }^{3}$ These domains are knowledge (the ability to interpret the information correctly, resulting in comprehension of information and knowledge about the quality scoring system) and attitude (beliefs regarding quality information including trust, appreciation, value and use of information). ${ }^{3}$
Focus group results showed that patients are likely to consider using pharmacy quality measures to choose their pharmacies; however, there is still some hesitation regarding how to utilise the information. Similar to the consumer choice model, Hibbard et $a t^{22}$ proposed that patients' awareness and understanding of quality information, and the perception of the information as useful were actions that needed to take place for quality-of-care information to be utilised by patients. This reinforces the need for patient education on quality reporting and the importance of the data in provider choice. Future research should examine the domains of quality that motivate patients to use pharmacy quality information.

Focus group statements showed that patients are likely to use pharmacy quality information if they are relocating to a new area. Similarly, results from a previous study of laypeople interpreting pharmacy quality information showed that patients thought quality information was informative but would only use it on relocation. ${ }^{20}$

Although some patients were hesitant to switch their pharmacies based on quality information, the majority would switch if it validated their personal experiences or they had a negative encounter with their pharmacies. It is possible that patients use emotional prompts in their selection of providers. In addition, patients have been found to be more sensitive to quality information if they are disappointed with their current provider. ${ }^{17}$ During a focus group discussion among patients in the UK, it was shown that provider quality information was only trusted when it confirmed patients' expectations. ${ }^{23}$ Although patients' own physicians were rated low, patients still would not change their physician if they had good experience. On the other hand, a Taiwanese survey showed that $75 \%$ of their respondents would change their own physician if he/she performed badly on a quality report. ${ }^{8}$ Patients have been noted to use quality information to avoid bad providers rather than choose
Figure 1 Value of quality measure in evaluating a community pharmacy $(\mathrm{N}=34)$.

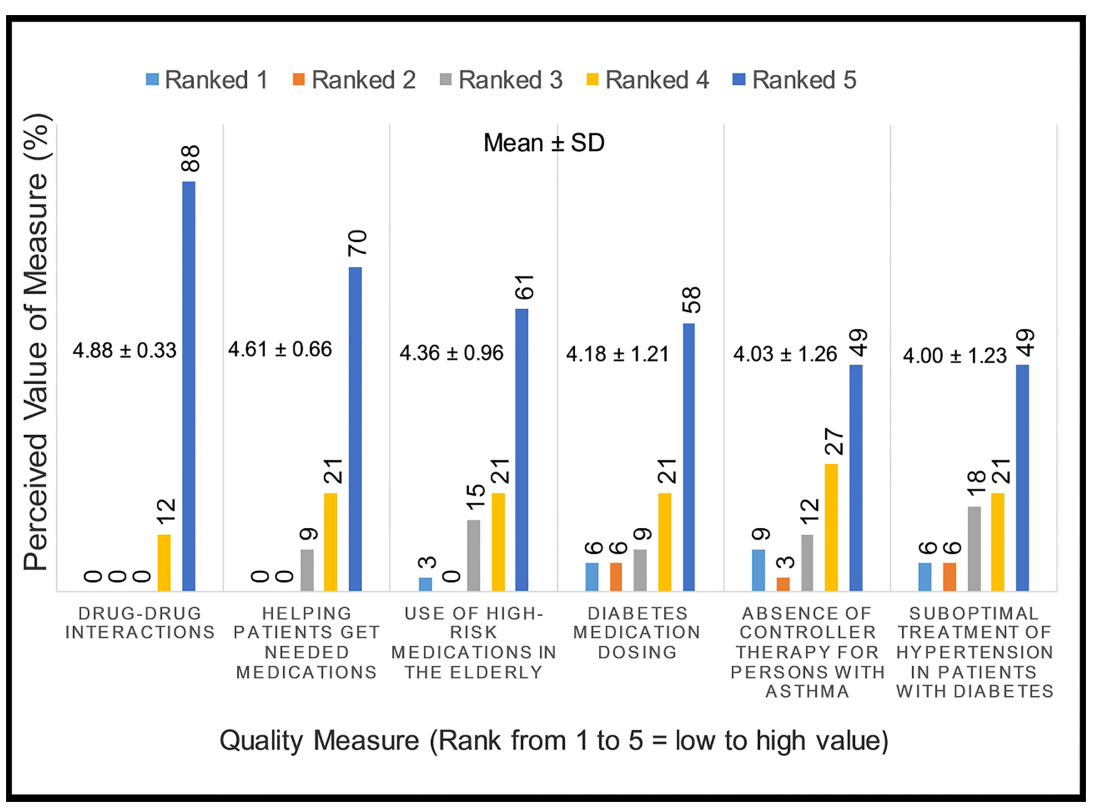


good providers. Hence, patients appear to use quality reports to evade poor-quality providers rather than seek providers with the best quality. ${ }^{24}$

Patients' opinion on whether they would use quality information to switch their pharmacy also seemed to differ by the geographical location in which they lived. Compared with patients living in the urban setting, those living in the rural setting were less likely to indicate their potential use of community pharmacy quality measures to switch their pharmacy. Reasons for participants' hesitation included established personal relationships with their pharmacists, calibre of the two pharmacies in the town, and the low number of pharmacies available in the area which limited their choice. In a review by Faber et $a l l^{3}$ it was discussed that restricted healthcare provider access clearly influences the weight given to using quality information in provider choice. $\mathrm{Xu}^{25}$ proposed that the use of a single community pharmacy by patients is likely to improve the quality of services received by a patient. With only two community pharmacies in the rural area utilised in this study, it is possible that patients only use a single pharmacy to fill their prescriptions, thus increasing the quality of services they receive and the merit of the pharmacies to patients. On the other hand, rural communities are typically served by independent community pharmacies which have to deal with lower prescription volumes compared with urban chain pharmacies. Dispensing lower numbers of prescriptions may have created more opportunities for personalised patient care services, thereby increasing patient satisfaction and limiting the possibility of a pharmacy switch. ${ }^{26}$

On the basis of the focus group statements, patients thought certain quality measures might be more useful than others in choosing a pharmacy. A previous study that examined which quality indicators were relevant or useful to patients when choosing a health plan showed a large amount of variation in the salience of different indicators. ${ }^{5}$ In the present study, patients were not likely to use suboptimal treatment of hypertension in patients with diabetes and absence of controller therapy in persons with asthma as quality measures to choose/switch their pharmacies. The survey results in this study also showed that these two appropriateness measures were the least understood by patients. It is possible that the hesitation to use these measures to choose or switch their pharmacies is due to insufficient knowledge of the measure and limited understanding of how to utilise the measure in their decision-making. Similarly, Hibbard and colleagues showed in their study that poorly understood quality indicators were viewed as not important when choosing a health plan. In Hibbard et $a l$ s study, patient comprehension of measures was related to the perceived salience of the measure. If patients do not understand pharmacy quality measures, they are likely to dismiss them as unimportant. ${ }^{19}$ On the other hand, since patients are not knowledgeable enough to understand appropriate drug therapy, their perceived importance and use of appropriateness quality measures in the evaluation of a pharmacy will be low.

The focus group and survey results from this study showed that the quality measure drug-drug interactions would be used by patients to choose or switch a pharmacy. In addition, drug-drug interactions were ranked the highest in value among all the specific measures that would be used in evaluating a pharmacy. Previous studies have shown that safety measures are important to patients when choosing a physician. ${ }^{4}{ }^{27}$ Similarly, Shiyanbola $e t a l^{20}$ showed that among laypeople who discussed community pharmacy quality measures, these individuals valued drugdrug interactions more highly compared with other quality measures. Medication safety seems to be a major concern for patients and pharmacists are positioned to handle this task. This study shows that patients rely on their pharmacists to ensure their medicines are not harming them and would use pharmacy quality information that reflects patient safety standards to select pharmacies. Quality reports may be of greatest utility to patients if they only show quality measures that are of significance to patients or at least highlight such measures. ${ }^{28}$

Patients seemed to value specific measures depending on whether the condition associated with the measure was personal to them. However, participants thought their preference in using certain measures to evaluate their pharmacy could change if they developed the condition later. Newly diagnosed patients have been reported to have increased sensitivity to quality-of-care information when choosing a health provider. ${ }^{17}$ It is possible that quality information only becomes relevant to users when a need is identified.

On the basis of focus group statements, patients were concerned about the credibility of public reported quality information and the rating systems that guided them. Past research has shown that patients do not use quality measures information because of a lack of trust in the data. ${ }^{3}$ In addition, participants were likely to use quality information to choose a pharmacy based on certain conditions including being knowledgeable of such information. Werner and $\mathrm{Asch}^{29}$ concluded that public reporting had a limited ability to influence patients' choice. However, patients' use of public reports may influence their selection of health providers if they are aware of the availability of report cards, understand them, trust them, and are willing and able to use this information in their provider selection process. ${ }^{2}$

Study limitations include the small sample size, limited geographical area, and predominantly Caucasian sample population which limits the ability to generalise the study findings to other racial/ethnic groups. The definition of the adherence measure, helping patients get medications, may have described access to medication as the major cause of adherence, though there are many other causes of non-adherence and several interventions to improve adherence. Future research should consider if the use and 
preferences for pharmacy quality measures might vary with patient characteristics such as race/ethnicity, healthliteracy level, language proficiency and education level, and if pharmacy measures that reflect these preferences can be developed and tested. In addition, it will be important to determine what dimensions of public reports are important to patients, especially considering the Survey of Consumer Experience with Pharmacy Services. ${ }^{30}$ Also, more studies should assess the use and preferences of minority patient populations for pharmacy quality report content, design and dissemination, and explore the best methods for refining pharmacy public reports to reflect those preferences.

\section{CONCLUSION}

Community pharmacy quality measures, when publicly available, may influence patients' choice of community pharmacies and their likelihood of switching their pharmacies, depending on individual preferences, patient geographical location and the availability of pharmacies in the area. The results of this study showed that patients value all pharmacy quality measures but perceive medication safety measures to be more important.

Acknowledgements The authors would like to acknowledge Trent Harris and Alicia Christensen who helped with the data collection and coding of the focus group transcripts. They also thank David Nau, President of Pharmacy Quality Solutions (Senior Director for Quality Strategies, PQA at the time of the study) for providing advice and direction for this study.

Contributors Both the authors designed the study. 00S was involved in data collection and data analysis. OOS wrote the manuscript and JRM critically revised the content. Both authors approved the final version of the manuscript.

Funding This work was supported by the Community Pharmacy Foundation (grant number 122)

Competing interests None.

Patient consent Obtained.

Ethics approval South Dakota State University Institutional Review Board.

Provenance and peer review Not commissioned; externally peer reviewed.

Data sharing statement No additional data are available.

Open Access This is an Open Access article distributed in accordance with the Creative Commons Attribution Non Commercial (CC BY-NC 4.0) license, which permits others to distribute, remix, adapt, build upon this work noncommercially, and license their derivative works on different terms, provided the original work is properly cited and the use is non-commercial. See: http:// creativecommons.org/licenses/by-nc/4.0/

\section{REFERENCES}

1. Institute of Medicine. Crossing the quality chasm: a new health system for the 21st century. Washington, DC: National Academy Press, 2001.

2. Robinowitz DL, Dudley RA. Public reporting of provider performance: can its impact be made greater? Annu Rev Public Health 2006;27:517-36.

3. Faber M, Bosch M, Wollersheim H, et al. Public reporting in healthcare: how do consumers use quality of care information? A systematic review. Med Care 2009;47:1-8.
4. Hibbard J, Pawlson LG. Why not give consumers a framework for understanding quality? Jt Comm J Qual Saf 2004:30:347-51.

5. Hibbard $\mathrm{JH}$, Jewett JJ. What type of quality information do consumers want in a health care report card? Med Care Res Rev 1996;53:28-47.

6. Longo DR, Everet KD. Health care consumer reports: an evaluation of consumer perspectives. J Health Care Financ 2003;30:65-71.

7. Boscarino JA, Adams RE. Public perceptions of quality care and provider profiling in New York: implications for improving quality care and public health. J Public Health Manag Pract 2004;10:241-50.

8. Cheng SH, Song HY. Physician performance information and consumer choice: a survey of subjects with the freedom to choose between doctors. Qual Saf Health Care 2004;13:98-101.

9. Schneider EC, Epstein AM. Use of public performance reports: a survey of patients undergoing cardiac surgery. JAMA 1998;279:1638-42.

10. Robinson S, Brodie M. Understanding the quality challenge for health consumers: the Kaiser/AHCPR Survey. Jt Comm J Qual Improv 1997;23:239-44.

11. Nursing Home Compare. http://www.medicare.gov/ nursinghomecompare/search.html (accessed 8 May 2014).

12. Hospital Compare. http://www.medicare.gov/hospitalcompare/search html (accessed 8 May 2014).

13. Pharmacy Quality Alliance. PQA endorsed set of measures 2006. http://pqaalliance.org/files/PQAMeasureDescriptionsFor Demonstrations.pdf (accessed 30 Sep 2011).

14. Pillittere-Dugan D, Nau DP, McDonough $\mathrm{K}$, et al. Development and testing of performance measures for pharmacy services. J Am Pharm Assoc 2009;49:212-19.

15. Hibbard JH, Berkman N, McCormack LA, et al. The impact of a CAHPS report on employee knowledge, beliefs, and decisions. Med Care Res Rev 2002;59:104-16.

16. Wedig GJ, Tai-Seale M. The effect of report cards on consumer choice in the health insurance market. $J$ Health Econ 2002;21:1031-48.

17. McCormack LA, Garfinkel SA, Hibbard JH, et al. Health plan decision making with new Medicare information materials. Health Serv Res 2001;36:531-54.

18. Schultz J, Thiede CK, Feldman R, et al. Do employees use report cards to assess health care provider systems? Health Serv Res 2001:36:509-30.

19. Hibbard JH, Jewett JJ. Will quality report cards help consumers? Health Affairs 1997;16:218-28.

20. Shiyanbola OO, Mort JR, Lyons K. Advancing the utility of community pharmacy quality measures: a qualitative study. J Am Pharm Assoc 2013;68:400-7.

21. Shiyanbola OO, Mort JR, Harris T, et al. Exploring consumer understanding and preferences for pharmacy quality information. Pharm Pract 2014;12:468.

22. Hibbard JH, Harris-Kojetin L, Mullin $\mathrm{P}$, et al. Increasing the impact of health plan report cards by addressing consumers' concerns. Health Aff (Millwood) 2000;19:138-43.

23. Marshall MN, Hiscock J, Sibbald B. Attitudes to the public release of comparative information on the quality of general practice care: qualitative study. BMJ 2002;325:1278.

24. Arnold SD. Improving quality health care: the role of consumer engagement, Robert Wood Johnson Foundation Issue Brief. Page 1-6.

25. Xu T. Choice of and overall satisfaction with pharmacies among a community-dwelling elderly population. Med Care 2002;40:1283-93.

26. Fraher E, Slifkin RT, Smith L, et al. How might the medicare prescription drug, improvement, and modernization Act of 2003 affect the financial viability of rural pharmacies? An analysis of reimplementation prescription volume and payment sources in rura and urban areas. J Rural Health 2005;21:114-21.

27. Hibbard JH, Greene J, Daniel D. What is quality anyway? Performance reports that clearly communicate to consumers the meaning of quality of care. Med Care Res Rev 2010;67:275-93.

28. Peters E, Dieckmann N, Dixon A, et al. Less is more in presenting quality information to consumers. Med Care Res Rev 2007;64:169-90.

29. Werner RM, Asch DA. The unintended consequences of publicly reporting quality information. JAMA 2005;293:1239-44.

30. Pharmacy Quality Alliance. Survey of consumer experiences with pharmacy services. http://pqaalliance.org/measures/survey.asp (accessed 7 May 2014). 